\title{
DE RESISTÊNCIAS À APRENDIZAGEM DA LÍNGUA INGLESA
}

\section{ON RESISTANCE TO THE ENGLISH LANGUAGE LEARNING}

\author{
Rosane Rocha Pessoa* \\ Joana Plaza Pinto
}

\section{RESUMO}

Este trabalho analisa narrativas sobre o contexto e as razões de desistência do estudo do inglês como língua estrangeira, especificamente entre estudantes e professoras/es da Faculdade de Letras da Universidade Federal de Goiás. O objetivo é compreender os significados culturais e as práticas identitárias das/os participantes em relação ao papel hegemônico do inglês como língua estrangeira no Brasil. Os resultados mostram que a desistência ocorreu em diferentes contextos educacionais e que a dificuldade com a língua inglesa é vista como limitação individual, reforçando a noção de aprendizado focado no indivíduo, nesses casos narrados como fracassados. Há ainda identificações antagônicas e aparentemente contraditórias sobre a construção da língua inglesa no mundo hoje. A partir da noção de babitus, aponta-se que as narrativas sobre o inglês legitimam o lugar de autoridade dessa língua.

Palavras-chave: estudantes de Letras; língua inglesa; hegemonia; resistência.

\section{ABSTRACT}

This paper analyses narratives of students and teachers from the Faculdade de Letras at the Universidade Federal de Goiás concerning the time and the reasons why they gave up studying English as a foreign language. It is aimed at understanding the college cultural meanings and identity practices with respect to the hegemonic role of English as a foreign language in Brazil. The research shows that the participants gave up studying English in different educational contexts and that the difficulty with English is seen as an individual limitation, reinforcing the notion of learning focused on the individual, in this case narrated as unsuccessful. Besides, it indicates that they disapprove of English and produce apparently contradictory narratives about the English language construction in the world today. Based on the notion of babitus, it is claimed that the narratives about English legitimize the place of authority of this language.

Keywords: students of Letras; English language; hegemony; resistance.

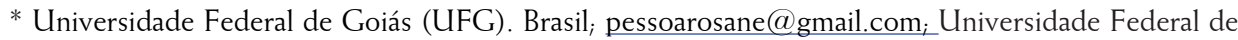
Goiás (UFG).Brasil. joplazapinto@gmail.com
} 
Certain languages such as English bave been found to be playing a begemonic role. RAJAGOPALAN (2001, p. 26)

\section{INTRODUÇÃO}

Não parece haver dissenso sobre a presença da língua inglesa em vários países e esferas de atividade - da ciência à publicidade - (ORTIZ, 2004) e, consequentemente, sobre a necessidade da língua inglesa nos meios acadêmicos, com o argumento de que as/os profissionais dessa área lidam com diversas línguas e deveriam dominar essa que é a língua na qual se veicula grande parte do conhecimento produzido no mundo (MOITA LOPES, 2003) e na qual também o conhecimento que é produzido aqui poderia ou deveria ser veiculado (LEFFA, 2001). Não menos raro é o discurso de resistência em relação a essa língua, expresso muitas vezes por um antiamericanismo (ASSIS-PETERSON e COX, 2007; LACOSTE, 2005).

Da observação de ambas as ideias, nasceu esta pesquisa, produzida como uma iniciativa para compreender a circulação de discursos sobre língua inglesa entre estudantes de diferentes Licenciaturas oferecidas pela Faculdade de Letras da UFG. Essa compreensão só é possível com um perfil amplo e detalhado quantitativo e qualitativo do conjunto de estudantes da Faculdade, como já tem sido iniciado por alguns poucos trabalhos (MELLO; REES; TELES-BOTTER e PESSOA, 1996; PESSOA; SEBBA e GOMES, 2009). No entanto, procuramos com esta pesquisa apresentar mais uma gama de elementos para essa compreensão, analisando narrativas de estudantes e professoras/es da Faculdade de Letras da UFG acerca do momento e das razões pelas quais desistiram de estudar a língua inglesa e da sua relação com essa língua. O objetivo deste artigo, portanto, é apresentar os enunciados encontrados nas narrativas e, assim, apontar algumas características do discurso sobre língua inglesa entre estudantes e professoras/es de Letras. Nossas perguntas de pesquisa são duas: 1) Em que momento e por que razões os/ as participantes desistiram de estudar a língua inglesa?; 2) Qual é a relação dos/as participantes com a língua inglesa?

Para respondê-las, nos fundamentamos num grupo de estudos que interpreta a circulação do inglês como integrando um conjunto político e social no mundo globalizado (ASSIS-PETERSON e COX, 2007; COX e ASSIS-PETERSON, 2008; LACOSTE, 2005; MIGNOLO, 2003; MOITA LOPES, 2003; PENNYCOOK, 2007; RAJAGOPALAN, 2001) e a língua como um objeto simbólico, e não como uma estrutura (BLOMMEAERT, 2005; BOURDIEU, 1996). 


\title{
1. FUNDAMENTAÇÃO TEÓRICA
}

Cox e Assis-Peterson (2008), em um artigo sobre o drama do ensino de inglês na escola pública brasileira, argumentam que a história brasileira de ensino dessa língua é de fracasso, o que se deve aos 35 anos (de 1961 a 1996) de não obrigatoriedade da língua estrangeira no ensino básico público brasileiro. Ressaltam que, no final de década de 1970, houve um grande crescimento de escolas de idiomas resultante da demanda das classes médias e alta, e o método funcional e comunicativo funcionou bem nas escolas que tinham as condições ideais garantidas, tais como turmas pequenas e homogêneas quanto ao nível de domínio da língua, professores proficientes, qualificados e bem remunerados, carga horária generosa etc. Afirmam ainda que, nos cursos de Letras, esse método funcionou apenas razoavelmente devido à dificuldade de reproduzir essas condições ideais e que, nas escolas regulares, esse método foi sequer implementado.

As autoras argumentam que, embora os documentos complementares à LDB 9394, de 1996, - Parâmetros Curriculares do Ensino Fundamental para as Línguas Estrangeiras (PCNLE), Parâmetros Curriculares Nacionais para o Ensino Médio (PCNEM) e Orientações Curriculares para o Ensino Médio (OCEM) -,

\begin{abstract}
catalisem as tendências de ruptura com o paradigma tradicional de ensino de língua, apontado, por muitos, como o principal responsável pelo fracasso do ensino de LE, não há sinais de que eles possam vingar e produzir bons frutos. [...]. Além das críticas advindas dos pares por divergência de ponto de vista em relação a finalidades, competências, teorias e métodos, [...] os documentos também são desacreditados por aqueles a quem se destinam, professores do ensino fundamental e médio, mediante o argumento de serem herméticos, além de impositivos - "de cima pra baixo" -, não espelhando os anseios e a realidade da comunidade escolar. (p. 34)
\end{abstract}

Outros aspectos que, segundo as autoras, emperram o ensino de LE são: baixos salários, desvalorização da profissão, ausência de tempo para estudo, baixo status da língua estrangeira na grade curricular, currículos de Letras conservadores, relação disfuncional entre teoria e prática, distância entre universidade e ensino básico e entre pesquisa e ensino etc. A situação de carência particularmente aguda da escola pública já havia sido mencionada em outro estudo das duas autoras (ASSIS-PETERSON e COX, 2007) e no de Celani (2003, p. 20), segundo as quais

[o] ensino de língua estrangeira, particularmente do inglês, encontra-se totalmente à deriva, com professores, pais e alunos muitas vezes se perguntando a mesma coisa: O que estamos fazendo aqui? Para que servirá esta tentativa frustrada de se ensinar/ aprender uma outra língua? 
Nesse contexto, parecem se salvar apenas as escolas de línguas, lugar ideal de aprendizagem de língua estrangeira no Brasil, o que se confirma nos estudos de Barcelos (1995), Oliveira e Mota (2003), Coelho (2006) e Borges, Lago e Fernandes (2009). O estudo de Barcelos (1995, p. 78) foi realizado com estudantes do curso de Letras em uma universidade federal do sudeste brasileiro, e os seguintes aspectos são destacados a respeito do curso de línguas: "eficácia do método e dos professores, rapidez do ensino, aprendizagem como o recebimento de conhecimentos transmitidos e aprendizagem sem esforço". A autora afirma ainda que curso de línguas e escola pública, na visão dos estudantes de seu estudo, ocupam posição antagônica, sendo o primeiro concebido como bastante positivo e o segundo como bastante negativo em relação tanto ao tipo de ensino quanto aos professores.

As críticas aos cursos de Letras têm sido também frequentes (BARCELOS, 1999; VIEIRA-ABRAHÃO e PAIVA，2000; CELANI，2001; LEFFA，2001; CASTRO, 2001; GIMENEZ, 2004; BARCELOS, BATISTA e ANDRADE, 2004; COX e ASSIS-PETERSON, 2008), mas aqui interessa focalizar a crítica de Cox e Assis-Peterson (2008) à baixa carga horária dedicada às disciplinas de língua, literaturas e formação profissional em língua inglesa na licenciatura dupla (menos de 400 horas-aula), o que dificulta lidar com o problema do desnível dos/as alunos/ as ingressantes. Afirmam que o que vem acontecendo é que a minoria dos/as que entram com domínio da língua é dispensada e a maioria com pouco domínio da língua "não consegue ir além do nível pré-intermediário, formando, portanto, muito mal os professores de inglês" (COX e ASSIS-PETERSON, 2008, p. 50).

No curso de Letras da UFG, a licenciatura dupla existiu até 2004 e a carga horária das disciplinas ministradas em língua inglesa era de 1.472 horas, não sendo, portanto, um problema no sentido dado por Cox e Assis-Peterson (2008). Mesmo assim, havia um considerável número de alunas/os que abandonavam a habilitação dupla, Português-Inglês, e optavam pela única, Português, o que nos motivou a fazer uma pesquisa (MELLO, REES, TELES-BOTTER e PESSOA, 1996) para examinar as razões por que isso aconteceu nos anos 1993, 1994 e 1995. Os instrumentos utilizados foram questionários e os extratos do histórico escolar dos alunos. Os resultados mostraram que muitos alunos que abandonaram o curso tinham uma visão idealizada da língua e do curso, impedindo que eles lidassem com a realidade objetiva do processo de aprendizagem de língua estrangeira. Alguns apontaram como problemas do curso o constrangimento diante dos colegas com maior competência linguística e o fato de que os professores dão aulas só para os que sabem inglês. 
Algumas medidas foram tomadas depois deste estudo e as que continuam sendo postas em prática são as adotadas nas disciplinas de língua inglesa: passou-se a discutir o processo de ensino-aprendizagem de línguas estrangeiras e as estratégias de aprendizagem que podem ser utilizadas para auxiliar nesse processo; incluiu-se o ensino de escrita acadêmica; e implementou-se o trabalho com estratégias de leitura. Quanto à experiência de começar as aulas no nível iniciante para atender aos estudantes com nenhum conhecimento da língua, ela foi modificada, pois os alunos de uma turma piloto terminaram o curso com um nível aquém do que se atingia anteriormente. Assim, o que se faz hoje é revisar conteúdos do nível elementar nos dois primeiros meses de aula e depois começar com os de nível pré-intermediário.

Tal decisão de iniciar as aulas de inglês no nível pré-intermediário se deve a três fatores: a língua é ensinada no ensino regular por oito anos, as aulas devem contemplar alunos que chegam ao curso tanto com pouco quanto com um maior conhecimento da língua, e o curso deve garantir que eles saiam com uma competência linguística que permita o ensino em qualquer contexto. De fato, exigir dos alunos um desenvolvimento linguístico mais rápido é uma forma de prepará-los não apenas para a leitura e discussão de textos literários nas disciplinas de literatura de língua inglesa, ministradas a partir da segunda metade do curso (AISSA, 2009), mas também para a ruptura do ciclo vicioso que se instaurou no ensino de línguas no Brasil, que é o de que os estudantes saem dos cursos de Letras com pouco domínio da língua-alvo (BASSO, 2006), e, ao se tornarem professores das escolas regulares, se veem impossibilitados de garantir a aprendizagem da língua pelos estudantes (BASSO, 2006; COELHO, 2006).

Em outra pesquisa (PESSOA, SEBBA; GOMES, 2009, p. 419) sobre o curso de Letras da UFG, realizada entre 2006 e 2009, constatou-se que a mudança da grade curricular anual para a semestral não trouxe alterações em termos de horas, pois "os alunos têm regularmente feito 1.488 horas de disciplinas ministradas em língua inglesa". A pesquisa teve como objetivo comparar o conhecimento linguístico ${ }^{1}$ e o teórico-profissional ${ }^{2}$ de alunas/os de inglês nas grades curriculares anual e semestral com base na percepção de professoras/es e alunas/os. Os dados foram coletados em cinco turmas de inglês, duas da grade curricular anual $\left(4^{\circ}\right.$ ano de 2006 e $5^{\circ}$ ano de 2006) e três da grade curricular semestral (uma turma do $6^{\circ}$

1 Quanto ao conhecimento linguístico, as/os participantes avaliaram o conhecimento das habilidades de compreensão oral e escrita e de produção oral e escrita, bem como o de gramática, pronúncia e vocabulário.

2 Quanto ao conhecimento teórico-profissional, as/os participantes avaliaram os conhecimentos teórico (teorias de aquisição de línguas, abordagens e métodos de ensino etc.) e o técnico (gerenciamento de sala, tempo de fala do professor, aplicação de exercícios e tarefas etc.). 
período de 2007 e duas turmas do $6^{\circ}$ período de 2008). Foram considerados para análise 53 participantes, das/os quais 23 declararam ter começado o curso como iniciantes e, embora muitos delas/es tenham mencionado dificuldade no início, especialmente com as habilidades orais, evidenciou-se, nos dados, que tiveram um desenvolvimento linguístico maior do que as/os que chegaram com uma boa competência linguística. Além disso, os dados mostram que as/os professores da área entendem que a maioria das/os estudantes - o que inclui as/os que ingressaram no curso com pouco conhecimento da língua - termina o curso com fluência, atingindo níveis que variam de intermediário a avançado.

Embora essa última pesquisa mostre que haja várias/os alunas/os que optam por inglês e são bem-sucedidas/os, a anterior evidencia que há as/os que desistem e são estas/es o foco deste estudo.

Tanto a literatura disponível sobre o tema (ASSIS-PETERSON e COX, 2007; LOPES, 2004; MASTRELLA, 2007; ORTIZ, 2004; RAJAGOPALAN, 2004) quanto as nossas experiências com estudantes da Faculdade de Letras, percebese que a relação das/os brasileiras/os com o inglês é ambivalente. Ambivalente porque é a língua que se coloca como necessária e imposta, a língua hegemônica (RAJAGOPALAN, 2001) que ao mesmo tempo serve para fazer contato com outras pessoas no mundo todo e para nos subjetivar como outro na nossa própria língua (MASTRELLA, 2007). Como lidar com essa ambivalência numa Faculdade de Letras que ensina essa e outras línguas? Como lidar criticamente com o discurso do mercado - "você precisa de inglês!" - e oferecer uma reflexão transgressora e libertadora do uso dessa língua?

Não resta dúvida de que vários idiomas constituem o mundo contemporâneo, mas, como afirma Ortiz (2006, p. 17), "a globalização declina-se preferencialmente em inglês", língua essa que, apesar de estar associada ao imperialismo norteamericano, pode ser desprendida de suas raízes, ou seja, desterritorializada, apropriada e ressignificada por falantes de qualquer língua materna. Destacamos aqui a expressão "pode ser", pois sabemos que o ensino da língua inglesa circula de diferentes maneiras pelo globo, incluindo formas culturais de afirmação das culturas norteamericana e britânica, conferindo a esta língua territórios, pátrias e políticas culturais que lhes são próprias. Apesar disso, acreditamos que essa língua pode ser desterritorializada, tendo em vista as apropriações já conhecidas (HOOKS, 1994; ANZALDÚA, 1999; MIGNOLO, 2003). É isso o que faz Hooks (1994, p. 174175):

Quando eu preciso dizer palavras que fazem mais do que simplesmente refletir ou se dirigir à realidade dominante, eu falo o vernáculo negro. Lá, nesse lugar, nós fazemos 
o inglês fazer o que nós queremos que ele faça. Nós tomamos a língua do opressor e a viramos contra ela mesma. Nós fazemos das nossas palavras uma fala contrahegemônica, liberando-nos nós mesmos na linguagem.

Também Assis-Peterson e Cox (2007) defendem uma posição pragmática em relação ao inglês, ao mesmo tempo em que criticam duas posições: as ingênuas, pois explicam a difusão do inglês pela simplicidade da gramática, pela afinidade com a mídia, com a técnica, com a ciência e com o progresso e, sobretudo, por seu caráter neutro como meio de comunicação entre diferentes línguas maternas; e as posições críticas, que veem o inglês como produto do imperialismo norteamericano e acreditam que falar essa língua contribui para fortalecer o capitalismo e manter a ordem existente. Para as duas autoras, precisamos nos apropriar dessa língua para produzir discursos contra o poder do inglês e do discurso neoliberal que fala por meio dele, já que tais discursos produziriam poucos efeitos se enunciados por meio de línguas locais.

Como todos esses discursos são articulados, ou não, pelas/os estudantes e professoras/es da Faculdade de Letras da UFG para interpretar suas experiências de desistência de estudo da língua inglesa? Se é certo que "o 'inglês de verdade" parece traduzir-se como o inglês que realmente dá poder ao falante de fazer-se legítimo, o inglês que é a língua do poder por permitir acesso a uma determinada rede social" (MASTRELLA, 2007, p. 228), como essa ideia coaduna e/ou contrasta com as narrativas de pessoas que, em algum momento de sua trajetória, desistiram dessa língua de poder legítimo?

Utilizaremos aqui a compreensão de Bourdieu (1996) para as práticas linguísticas. Este autor afirma que a língua é um objeto simbólico e nega a autonomização da língua (visão da língua como estrutura) em relação às suas condições sociais de produção, reprodução e utilização. A língua integra o discurso como conjunto de enunciados controlados por condições sociais de produção e utilização. Tais condições são dadas por regras práticas de distribuição e regulação do poder. Tais práticas são modeladas por disposições sociais do babitus linguístico, "que implicam uma certa propensão a falar e a dizer coisas determinadas (interesse expressivo), definida ao mesmo tempo como capacidade linguística de engendramento infinito de discursos gramaticalmente conformes e como capacidade social que permite utilizar adequadamente essa competência numa situação determinada [...]" (BOURDIEU, 1996, p. 24). Como explica bem Blommaert (2005), o babitus é um conjunto de princípios geradores e organizadores de práticas e representações que não pressupõem uma consciência visando fins ou um domínio expresso das operações necessárias para atingi-los, são "características 
da estrutura social que se tornam um padrão 'normal' ('habitual' e 'corporificado') de comportamento" (BLOMMAERT, 2005, p. 252), tendo, portanto, tal conjunto um efeito de "senso comum" ou "naturalização".

As narrativas que vamos analisar são a fonte para desenhar tais conjuntos, e, como procuraremos mostrar, se expressam por disposições (negativas e positivas) do babitus linguístico sobre o inglês.

\section{A PESQUISA}

Nos períodos destinados à realização da Prática como Componente Curricular ${ }^{3}, 20 \mathrm{a}$ 24 de abril de 2009 e 13 a 16 de outubro de 2009, foram realizadas as entrevistas da pesquisa, e mais tarde, a partir de novembro de 2009, foram feitas checagens de dados por meio da confrontação na análise. A entrevista semi-estruturada foi objetiva, com perguntas sobre o perfil da/o entrevistada/o preenchido em ficha própria antes da gravação: idade, sexo, cor/raça, período em que estuda (ou escolaridade e formação do/a professor/a), profissão; além de um conjunto de quatro perguntas simples e diretas sobre o tema: 1. Você já estudou inglês? Quando? Onde?; 2. Você desistiu de estudar inglês em algum momento da sua trajetória acadêmica? Quando? Por quê?; 3. O que você acha de inglês?; 4. Como você vê essa afirmação: "O mundo declina-se preferencialmente em inglês" (ORTIZ, 2006, p. 17).

Tais entrevistas curtas contemplaram um breve perfil da pessoa entrevistada e sua experiência de desistência do estudo de língua inglesa, incluindo as razões por que desistiu e sua visão dessa língua. Ao todo, foram entrevistadas 46 pessoas, sendo 40 estudantes e 6 professoras/es da Faculdade de Letras. As entrevistas foram realizadas por estudantes de diferentes Licenciaturas, sob nossa orientação, durante o desenvolvimento da atividade de Prática como Componente Curricular. As entrevistas foram transcritas pelas/os estudantes e conferidas por nós, pesquisadoras responsáveis. Na conferência, confrontamos dados inconsistentes, utilizando o critério de que todas as pessoas entrevistadas deveriam ter desistido,

3 A fim de atender à exigência da Resolução CNE/CP 2 (2002), que determina que os cursos de licenciatura devem dedicar "400 horas de prática como componente curricular, vivenciadas ao longo do curso", a Faculdade de Letras da UFG reserva até uma semana de cada semestre letivo para atividades de campo, sejam no âmbito escolar ou em outros contextos. A cada semestre, as/ os professoras/es efetivas/os elaboram projetos que definem o trabalho a ser realizado em campo pelas/os alunas/os, e estes, em grupos de até cinco, escolhem os projetos que querem desenvolver durante a semana dedicada à prática, ao final da qual devem entregar à/ao professor/a responsável um relatório elaborado com base nas observações realizadas. 
em algum momento da vida, de estudar língua inglesa, e, além disso, checando os preenchimentos de perfil e a organização das transcrições.

Depois dessa conferência, foram analisadas 41 entrevistas - 37 com estudantes e 4 com professoras/es -, tendo como parâmetros as duas seguintes razões para descarte das entrevistas: 1. algumas foram realizadas, por diferentes estudantes, com a mesma pessoa; 2. algumas pessoas entrevistadas afirmaram nunca ter desistido de estudar inglês, perdendo assim sua elegibilidade para os dados.

Das 41 pessoas selecionadas, 32 (78\%) eram mulheres e 9 (22\%) homens. As faixas etárias predominaram até 24 anos (61\%), sendo 10 (24\%) até 19 anos e $15(37 \%)$ de 20 a 24 anos. Há ainda um destaque para a faixa acima de 27 anos, chegando a atingir 14 (34\%) do total das/os entrevistadas/os em idades dispersas de 27 a 52 anos. Esse resultado tem relação com a aleatoriedade da amostra - a equipe de estudantes foi instruída para buscar aleatoriamente as pessoas entrevistadas, evitando apenas a Licenciatura em Inglês. Quanto às/aos estudantes, 22 (59\%) estavam matriculadas/os entre o $3^{\circ}$ e o $7^{\circ}$ períodos, tendo, portanto, a amostra uma grande concentração de estudantes na metade do curso. Sobre raça, 23 (56\%) das pessoas se declararam brancas, sendo 15 (37\%) pessoas negras (11 pardas e 4 pretas $)^{4}$. Sobre emprego, 24 (59\%) declararam trabalhar, 15 (37\%) não trabalham e 2 (5\%) não responderam. Temos, então, como referência, que a amostra apresenta predominantemente mulheres ( $78 \%$ da amostra total) brancas ( $68 \%$ das mulheres se declararam brancas), até 24 anos (68\% das mulheres tinham até 24 anos), cursando a metade do curso de Letras e predominantemente trabalhando ( $56 \%$ das mulheres da amostra se declararam empregadas).

\section{SOBRE DESISTÊNCIAS: MOMENTOS}

Das/os 41 participantes, 18 (44\%) (14 estudantes e 4 docentes) desistiram de estudar antes de entrar no curso de Letras ou em algum outro momento da vida acadêmica. Dessas/es 18, 3 afirmaram ter desistido na escola regular e 10, em escolas de língua. As/os outros 4 não mencionaram o momento da desistência. As principais razões apontadas para desistência são dificuldade com a língua, insucesso na aprendizagem, desgosto ou desinteresse pela língua e insatisfação com o método de ensino.

Dos 23 (56\%) participantes restantes, cuja desistência tem alguma relação com o curso de Letras, 4 não chegaram a fazer aulas de língua inglesa, pois não

4 As demais pessoas se declararam "amarelos" ou não declararam cor/raça. 
obtiveram classificação no vestibular para estudar inglês ${ }^{5}$. Cinco afirmam ter desistido porque tinham de fazer opção por uma habilitação (4 o fizeram pelo português), mas pretendem voltar e fazer a Habilitação em Inglês. Outra aluna também fez opção por português por falta de tempo e não menciona pretender voltar a cursar Inglês. Uma professora terminou o curso de Letras Português/Inglês, lecionou inglês no início e depois fez opção pela docência em língua portuguesa, por várias razões, mas, sobretudo, por não se sentir preparada e porque nunca gostou muito de inglês. Os outros 12 ( $29 \%$ da amostra total) desistiram nos dois primeiros anos do curso, sendo a principal razão o fato de as aulas de inglês não começarem no nível iniciante. Outras razões mais apontadas são o baixo desempenho nas aulas, a dificuldade com a língua e as/os professores.

A desistência nesses vários contextos evidencia uma falha no sistema educacional brasileiro, seja nas políticas colocadas em prática ou na atuação de professoras/es de todos os níveis, no sentido de combater a reprodução da desvantagem de estudantes e atender à grande demanda por esse "bem precioso" (LIN, 1999, p. 393) que se tornou a aprendizagem de língua inglesa contemporaneamente. Uma dessas falhas é a situação do ensino regular, como se verá a seguir.

\title{
3.1. Apagamento do ensino regular
}

Um resultado esperado, mas não de maneira tão contundente, é o fato de 20 participantes dos 41 , quase $50 \%$ da amostra, não terem sequer mencionado o ensino regular, 15 (37\%) terem apenas mencionado e 5 (12\%) terem criticado esse contexto de ensino, como se pode ver nos exemplos:

\begin{abstract}
A1: Já, já estudei quando eu fazia primário, e também no ensino fundamental, aquelas noções básicas, tipo, cores e essas coisas assim que todo mundo sabe, aí no ginásio também eu tive, e no $2^{\circ}$ grau também, mas sempre assim, não passava dessa noção básica, tipo "good morning" [risos].
\end{abstract}

\footnotetext{
5 Na UFG, a/o estudante faz vestibular para o curso de Letras do turno matutino sem modalidade definida. A opção por uma das seis habilitações do curso é determinada pelo percurso seguido pela/o estudante, após a realização de $75 \%$ das disciplinas do núcleo comum. Ao se matricular no curso de Letras, a/o estudante faz opção por uma das línguas estrangeiras oferecidas: Espanhol, Francês, Inglês ou Italiano. A definição da língua estrangeira, dentre as opções oferecidas no ato da matrícula, é feita pelo Centro de Seleção, considerando a ordem de classificação no Processo Seletivo. Assim, há estudantes que escolhem uma língua, mas não atingem a classificação necessária para cursá-la, o que não impede que elas/es tentem uma mudança de habilitação, por meio de surgimento de vaga, permuta ou teste de nível. Alguns/mas estudantes da amostra desta pesquisa desistiram não exatamente de cursar a língua inglesa, mas de insistir, ou seja, de tentar uma dessas três possibilidades de conseguir uma vaga para a Licenciatura em Inglês.
} 
A5: [...] aí tinha aquela coisa do verbo "to be", eu nunca aprendi, mas eu fiquei... [risos] o ensino médio inteiro aprendendo verbo "to be" e até hoje eu não sei o que é o verbo "to be", mas assim... mas alguém vai saber o que é. E aí aquela frase né? No caso, interrogativa, negativa, só fica nisso né? E palavrinhas né?

P4: Mas era um falso inglês, um arremedo de inglês.

Desses 5, 3 decidiram, nesse contexto, que não queriam estudar inglês por causa do insucesso na aprendizagem, do método de ensino e da dificuldade com a língua, e os 3 estavam no ensino médio quando tomaram essa decisão. Segue um desses depoimentos:

A9: [Desisti] no terceiro ano, cansei de inglês, eu não entendia nada e, quando eu prestei o vestibular e passei, eu escolhi outra língua podendo escolher inglês, escolhi o francês.

Tais depoimentos corroboram a situação de carência particularmente aguda da escola pública, conforme argumentam Celani (2003) e Assis-Peterson e Cox (2007). Em uma perspectiva mais ampla, Cox e Assis-Peterson (2008, p. 36-37) ressaltam que a "incompetência da escola pública em fazer dos filhos das classes menos favorecidas usuários do inglês vem colaborando, ano após ano, para a reprodução da atual ordem econômica e social". Nos termos de Bourdieu (1973), trata-se da incapacidade das escolas de tornar o babitus dessas/es estudantes compatível com o babitus que se pressupõe nesses contextos. As autoras afirmam que essa situação é atenuada nas escolas regulares particulares, já que a sua clientela pode pagar um curso de línguas, que é "um lugar projetado como ideal para aquisição do inglês" (2008, p. 36). No entanto, não se pode perceber isso nas narrativas das/ os participantes desta pesquisa, como será evidenciado na próxima seção.

\subsection{Curso de línguas: contexto ideal?}

Estudaram em curso de língua 25 (61\%) dos 41 participantes, e, ao contrário do que acontece com a escola regular, esse contexto é mencionado mesmo quando não foi vivenciado: "[Estudei] só na faculdade mesmo, nunca fiz nenhum cursinho de idiomas não" [A27]. No entanto, apesar de ser reconhecido, apenas 5 alunas afirmam ter uma visão positiva desse contexto. E, dessas 5, apenas 1 ainda estuda em curso de línguas, e outra chegou ao final do curso. A grande maioria dessas/es 25 estudou de um semestre a dois anos, e as principais razões da desistência são: falta de tempo, desgosto pela língua, insatisfação com o método, dificuldade com a língua e insucesso na aprendizagem, como se pode perceber nos depoimentos: 
A7: Eu acho que pelo método de ensino, essas coisas de decorar, eu não gostava disso $[\ldots]$.

A8: [Desisti] pela dificuldade que eu tenho na leitura, na fala e em me expressar em inglês.

A23: Sim, eu desisti nesse semestre quando eu estava fazendo o nível três, porque, como eu estou fazendo faculdade paralelamente, estava muito puxado o ensino de inglês. Eu não estava conseguindo conciliar os dois estudos.

P1: Desisti em vários momentos, acreditando que o que eu precisava naquele momento era suficiente, e também porque ainda não era momento de dar continuidade porque eu continuava desinteressado pelo inglês.

A grande desistência nesse contexto é um dado interessante, na medida em que, como vimos, é visto como o lugar ideal de aprendizagem de língua estrangeira no Brasil. Todavia, se as escolas de inglês fossem mesmo o contexto ideal de aprendizagem, elas já teriam feito a diferença na educação de língua inglesa no Brasil, dada a sua capacidade de proliferação não apenas nas capitais, mas também nas cidades menores. Ao contrário, como mostram os depoimentos das/os participantes deste estudo, esse parece ser também um contexto de fracasso no ensino de língua inglesa no cenário nacional, pois, mesmo quando aprovado pelas/os participantes, não se configura como um incentivo à continuidade do estudo da língua. Há, inclusive, o caso curioso de um aluno que afirma ter estudado nesse contexto, mas não se lembra onde e nem quando.

Esse resultado sugere o seguinte questionamento: para quem os cursos de língua são um lugar ideal de aprendizagem? E novamente inspiradas por Bourdieu (1973), vemo-nos diante da resposta de que tais cursos são um lugar ideal para estudantes de uma elite socioeconômica cujo babitus adquirido por meio da socialização em suas famílias e em seu grupo social é o capital cultural necessário para o sucesso nesse contexto escolar, já que os estudantes deste estudo certamente não fazem parte desse grupo, restando-lhes apenas a possibilidade de insucesso.

\subsection{Desistência nas aulas de inglês da Faculdade de Letras}

Conforme dito anteriormente, 12 (29\%) dos 41 participantes afirmam ter desistido por causa das aulas de inglês da Faculdade de Letras, e 5 apontaram o nível das aulas como o principal fator de desistência:

A3: [...] eu pensei que fosse começar do início, aquela coisa mais básica, mas muitas pessoas já tinham um nível muito bom na sala, eu percebi que não dava pra continuar $[\ldots]$. 
A11: $O$ que aconteceu, eu entrei na sala de aula, cheguei um pouco atrasada, uns cinco ou dez minutos atrasada e estava todo mundo conversando em inglês e eu, putz, o quê que eu estou fazendo aqui? Porque eu tinha pouca noção de inglês mesmo, o básico do básico. Aí eu, gente do céu, se for pra falar só inglês aqui eu estou ferrada. Aí eu comecei a me frustrar. [...] Aí depois ela [a professora] foi amenizando a situação. Foi ficando mais tranquilo, só que mesmo assim pra mim que tinha quase nenhuma noção de inglês, ainda estava meio complicado.

Essa visão de que para fazer inglês no curso de Letras da UFG é preciso entrar com boa competência linguística contradiz os resultados da pesquisa de Pessoa, Sebba e Gomes (2009), também realizada nesse contexto, pois, como vimos, dos 53 participantes, 23 declararam ter começado o curso como iniciantes e terminado com uma bom conhecimento da língua. Assim, também a afirmação de que todas/ os as/os alunas/os de uma turma de primeiro período conversam fluentemente em inglês demonstra uma percepção equivocada, embora se possa compreender a perplexidade advinda da falta dessa língua de poder legítimo.

Outra aluna deste estudo, que mencionou o nível das aulas, desistiu, ao contrário das outras cinco, por causa do nível muito básico das aulas, já que havia estudado quatro anos e meio em um curso de línguas:

A37: Fiquei muito frustrada porque eu imaginava que o inglês da faculdade fosse muito diferente do inglês do cursinho que eu fazia e não foi... Eu me sentia como uma criança nas aulas, começando do zero, porque eu já tinha uma base, mas não conseguia mostrar pros outros o que eu sabia. Eu ficava meio deslocada.

Depoimentos como esse justificam a decisão de não começar do nível básico, pois objetiva-se contemplar estudantes que chegam ao curso tanto com pouco quanto com um maior conhecimento da língua, bem como garantir que elas/es saiam com uma competência linguística que permita o ensino em qualquer contexto. Além disso, é uma forma de prepará-los para as disciplinas de literatura de língua inglesa (AISSA, 2009) e de romper com o ciclo vicioso mencionado por Basso (2006) e Coelho (2006).

Não obstante as decisões tomadas pelas/os professoras/es da área para lidar com essa situação, a heterogeneidade linguística é vista em contextos educacionais como uma das maiores dificuldades enfrentadas, pois, como se pode ver, divide as/os estudantes em dois grupos opostos: o das/os que sabem e o das/os que não sabem a língua-alvo, quando, na verdade, elas/es apresentam diferentes níveis de conhecimento dessa língua e, além disso, diferentes identidades, diferentes experiências educacionais, diferentes conhecimentos, diferentes experiências 
de vida etc. Por isso, essa oposição binária deve ser desnaturalizada, ou seja, é preciso que as/os estudantes se afirmem como pessoas que são mais do que apenas aprendizes da língua-alvo e que têm mais do que simplesmente dois níveis de conhecimento linguístico (sabem tudo ou não sabem nada) e que professoras/es de língua reconheçam e valorizem essas outras identidades que as/os estudantes trazem para sala de aula.

Também foram razões apontadas para a desistência o baixo desempenho nas aulas, a dificuldade com a língua e os professores, como se pode ver nos excertos:

A14: [Desisti] no ano passado, porque minha média estava muito baixa e eu resolvi dar um tempo.

A16: [Desisti por] achar o inglês um pouco difícil pra mim, porque eu não aprendi a lidar com os princípios linguísticos do inglês.

A20: Os professores de língua inglesa desestimulam aqueles que não conhecem a língua.

Entender que a diferença tem especificidades que devem ser valorizadas é fundamental para que estudantes e docentes rompam com o que Bourdieu (1996) chama de "violência simbólica", que é a imposição das representações de mundo e de significados sociais das classes dominantes sobre grupos das classes dominadas, de tal modo que tais representações são percebidas como legítimas. Como resultado, o insucesso na escola, ou ,nesse caso, na aprendizagem de língua inglesa, é atribuído não à desigualdade inicial do capital cultural valorizado e legitimado nos espaços educacionais, mas unicamente a uma deficiência cognitiva individual ou à falta de esforço. Vários depoimentos sobre a relação com a língua corroboram essa "teoria da privação ou sociocultural", que é definida por Ogbu (1978 apud CHARLOT, 2000, p. 26) como uma falta imputável à/ao própria/o estudante, que tem deficiências, lacunas, carências. Tais depoimentos serão discutidos mais detalhadamente na próxima seção.

\section{SOBRE RESISTÊNCIAS: INDIVIDUALIZAÇÕES DE DIFICULDADES E "NECESSI- DADE VIRTUAL" NO DISCURSO SOBRE LÍNGUA INGLESA}

Conforme o roteiro de entrevista propôs, além das razões da desistência do estudo, propusemos às pessoas entrevistadas que refletissem sobre sua visão da língua inglesa e seu papel no mundo globalizado. Confrontando as respostas sobre as razões com as visões sobre a língua, encontramos basicamente duas posições 
antagônicas acerca do papel da língua inglesa no mundo contemporâneo, ainda que não excludentes.

A primeira posição afirma que a língua inglesa é identificada com dispositivos de coerção e limitação, gerando resistência e disposições negativas: "a língua mais difícil de aprender", "a língua menos acessível", "a língua mais competitiva e mais disputada".

Da amostra, 27 estudantes (73\%) e 2 professoras/es identificam sua experiência de aprendizado da língua inglesa com dificuldade individual, associando explicitamente essa dificuldade como "limitação" pessoal, individual, localizada exclusivamente na própria pessoa, reforçando a noção de "aprendizado focado no indivíduo", nesses casos fracassados, em expressões como "tive um bloqueio", "tive medo", "não sabia mesmo", "não consegui aprender", "meu inglês é 'capenga’". Alguns trechos demonstram isso:

A2: Eu já passei por situações de ver alguém falando inglês e ficar assim, com vontade de entender tudo que a pessoa tá te falando, e muitas vezes não dá pra entender tudo, pela falta de conhecimento, mas dá muita vontade de poder entender.

A20: [...] não conseguia acompanhar a turma. Então eu me sentia ridícula nas aulas. Eu não conseguia entender o que a professora estava falando, eu não conseguia responder o que ela perguntava.

P4: [...] lia, conseguia entender bem a gramática, mas a conversação era travada. [...] Me saí muito bem, mas sempre bloqueada. Eu não consigo.

Essa predominância de disposições de limitação individual convive com limitações de outras ordens, ainda que em menor número, como a ideia de que a língua inglesa é menos acessível, sendo a mais competitiva e disputada:

A2: Infelizmente por causa da classificação no vestibular, pois são só 30 vagas pra inglês, então [...]. Não, não é bem desistir, não por vontade própria, eu queria, mas não me deixaram.

A9: Eu acho que é uma língua chata, não me interessa muito. Não sei, eu estudei pouco pra poder falar o que eu acho. Mas ela é necessária, eu tenho que aprender a falar mais pra frente, não agora.

Vale a pena destacar como disposição negativa o discurso da universalidade imposta da língua inglesa: por razões profissionais ou acadêmicas, a língua inglesa é repetidamente nomeada como "a língua universal" (5 estudantes usaram essa expressão exata ) e "a língua imposta" (3 estudantes usaram essa expressão): 
A5: [Estudo em escola de línguas] por causa da imposição mesmo, porque tinha aquela coisa de fazer uma língua estrangeira, o inglês é língua estrangeira universal.

A20: É verdade que todos os documentos, artigos acadêmicos, toda a produção de conhecimento hoje em dia é produzida em língua inglesa. Se você quer que as suas ideias sejam lidas, sejam conhecidas por um número maior de pessoas você precisa escrever em inglês. Até mesmo se você quer ter um conhecimento maior do que está sendo produzido no mundo você precisa conhecer o inglês. É uma necessidade que é imposta.

O discurso da universalidade imposta da língua inglesa depende fortemente, na amostra, de uma pressuposta "necessidade virtual da língua inglesa" (metade dos/ as estudantes e metade das/os professoras/es afirmam essa "necessidade"): é a língua inevitável, "importante", entrecruzada numa rede de capital simbólico acumulado (ou seja, valor e prestígio acumulado e naturalizado pelo babitus) muito mais do que capital prático (ou seja, ferramentas, habilidades e usos). Essa língua "universal" deve estar virtualmente disponível, ainda que seus objetivos práticos deslizem frouxamente - reforçando o aspecto virtual dessa necessidade. Notamos um bom exemplo disso no trecho de $\mathrm{A} 3$, em que a necessidade de saber inglês vai desde uma demanda "na universidade" genericamente definida, passando por supostos problemas de tradução de textos com inglês como língua-fonte, até a pronúncia das palavras (quais situações de pronúncia e para que tais situações?). Ainda que reconheçamos que as necessidades listadas por A3 podem ser reais, precisamos levar em consideração que 1. estas necessidades não são explicitamente da pessoa que fala (objetivos de aprendizagem) e também 2. há uma ênfase progressiva e exagerada na adjetivação do inglês (importante, fundamental, necessário), articulada com 3. mudanças de critério para listar as necessidades (universidade, tradução de textos, apresentar trabalhos, pronunciar palavras), tudo isso refletindo que 4 . circulam ideias difusas e heterenômicas para justificar o aprendizado do inglês:

A3: [...] o inglês não é nem importante, ele é fundamental, é necessário, não tem como a pessoa, principalmente na universidade assim. Quando você pega textos traduzidos às vezes você perde muito nessa tradução, então quando você tem acesso ao material em inglês mesmo, é diferente, até apresentar um trabalho, pronunciar as palavras bem, então assim não tem como ficar sem.

O discurso da "língua universal" é articulado tanto de forma negativa, associada a uma "universalidade imposta", quanto de forma positiva, associado a uma rede simbólica de oportunidades e interesses inegáveis. Nesse ponto, a língua inglesa é identificada com alto capital simbólico, gerando atração e disposições positivas: 
a língua obrigatória e necessária (como já discutimos antes), a única resposta linguística para a comunicação mundial, o conhecimento linguístico principal para a vida contemporânea, a habilidade linguística essencial para o mercado de trabalho:

A4: [...] é basicamente a língua universal, só que eu acho que hoje que em dia não é mais diferencial, é mais que uma obrigação você saber inglês, porque todo lugar que você vai tudo fala inglês, então é o meio mais fácil de comunicar [...]

A10: [A importância do inglês é] [p]ra se comunicar. Porque qualquer lugar que você vá tem alguém que sabe falar inglês.

A11: Eu tenho essa vontade de aprender inglês, acho que é super necessário. Inglês é a língua universal, a primeira língua digamos assim. É necessário que a gente tenha inglês.

A27: Com a língua [inglesa] você consegue se comunicar facilmente em qualduer lugar...

Notamos no grau de generalização dos trechos em destaque um acúmulo impressionante de capital simbólico. A fantasia de que em qualquer lugar do mundo alguém sabe inglês integra o conjunto discursivo das "necessidades virtuais" e apaga ou atenua os reais ganhos práticos do aprendizado e da prática dessa língua. Essa "virtualização" nos fez perguntar várias vezes: a língua inglesa "é" ou "deve ser" vista como necessária?

Numa mesma entrevista, encontramos identificações antagônicas. Essa aparente contradição tem relação direta com a visão ingênua sobre a construção da língua inglesa no mundo hoje, uma impressão de "inevitável imposição" e, ao mesmo tempo, "opressão cruel". Nesse sentido, foi possível perceber uma mistura simplista de duas das leituras do inglês apontadas por Assis-Peterson e Cox (2007, p. 5): "a leitura ingênua, que vê a mundialização da língua como natural e neutra, e a leitura crítica, fortemente timbrada pela ideologia nacionalista e antiimperialista, que a interpreta como mais uma instância da dominação americana sobre o mundo".

Esse tipo de mistura das duas leituras vem acompanhado de muita imprecisão de termos ("é uma língua universal") e argumentos confusos e pouco elaborados, atendendo a uma pressa em justificar a posição contraditória:

A7: Eu não acredito que a língua inglesa domina tanto assim, mas é interessante que a pessoa aprenda porque é exigido pelo contexto, pela economia, mas para mim, ela não exerce tanta influência não [...].

A27: Então pelo menos a primeira língua estrangeira tem que ser o inglês... Por outro lado eu sinto uma perda... Porque... Uma perda até cultural... Porque... Suponhamos a pessoa então... Porque que a pessoa vai querer estudar inglês... Ah... Eu vou querer estudar inglês pra me promover profissionalmente... Para eu conseguir um emprego melhor... 
A língua inglesa é exigida, mas não exerce tanta influência. A língua inglesa deve ser a primeira língua estrangeira e promove profissionalmente, mas é sentida uma perda "até cultural". O que fazer diante desta imposição senão resistir? No entanto, na maior parte das entrevistas, tal resistência não oferece síntese para a contradição percebida.

\section{CONCLUSÃO}

Uma síntese possível é aquela apontada por Pennycook (2007, p. 97): na superfície o debate é sobre línguas, mas trata-se sempre de um debate ideológico, que constrói o mundo e a metalinguagem que o descreve. Apontando para essa abordagem do ponto contraditório - não acreditar na imposição do inglês e viver a imposição como cobrança na vida acadêmica -, A20 observa:

[...] eu não acredito que seja o inglês, isso é um resultado da dominação americana, de um país que fala inglês. Se o país falasse qualquer outra língua essa língua seria utilizada. Então aí os aspectos que são levados em conta são mais aspectos econômicos, do que aspectos da língua em si. O inglês é uma língua como qualquer outra língua, como o português, como o francês. Se fôssemos nós, os brasileiros, a grande nação que dita as regras a serem seguidas pelos países subdesenvolvidos com certeza o que o povo estaria estudando seria português.... [risos].

Os mitos sobre a estrutura "mais fácil" do inglês para a internacionalização das comunicações (cf. PENNYCOOK, 2007) é desfeito no trecho em destaque e sua predominância sobre outras línguas é interpretada como uma política linguística e desnaturalizada. A20 parece pressentir que o êxito do poder da língua inglesa, sua autoridade e legitimidade como "língua inevitável", está subordinado ao que Bourdieu (1996, p. 89) chama de "confluência de um conjunto sistemático de condições interdependentes que compõem os rituais sociais". Esse êxito não depende da compreensão da autoridade da língua inglesa (suas vantagens práticas e simbólicas descritas objetivamente), mas antes é preciso que tal autoridade seja reconhecida enquanto tal para que possa exercer seu próprio efeito. E este reconhecimento é imediatamente naturalizado, impedindo a percepção da contradição "imposição/resistência" e garantindo a manutenção da idéia de que tal resistência é um sintoma de incompetências individuais e localizadas, e não o conjunto de um mapa de relações de poder entre línguas - ou seja, um mapa de políticas linguísticas internacionais. 
Para compreendermos esses engendramentos, temos que pensar no que Bourdieu (1996, p. 91) afirma sobre as manifestações de autoridade linguística: "Essas manifestações derivam sua eficácia específica do fato de que parecem encerrar em si mesmas o princípio de um poder que reside efetivamente nas condições institucionais de sua produção e de sua recepção". Os discursos sobre o inglês entre pessoas que desistiram de cursá-lo apresentam disposições, socialmente modeladas, que legitimam o lugar de autoridade dessa língua engendrando sua "necessidade virtual e inevitável", localizando, em sua maior parte, suas resistências como sintoma de incompetências e indisposições individuais.

Compreender essas disposições é um passo pedagógico importante contra a individualização do fracasso, "a deficiência como falta constitutiva do indivíduo" (CHARLOT, 2000, p. 27). Nesse sentido, professoras/es de língua inglesa devem estabelecer debates sobre a imposição e estratégias não ingênuas de resistência e se engajar na luta por visibilizar políticas linguísticas que desnaturalizem o lugar do inglês, ou seja, que confrontem seu babitus, promovendo não uma campanha contra esta língua, mas sua apropriação crítica e contra-hegemônica em tempos de globalização.

\section{REFERÊNCIAS BIBLIOGRÁFICAS}

AISSA, J. C. (2009). O ensino de literatura de língua inglesa e de inglês como língua estrangeira em cursos de letras: conflito de incompatibilidade? In: II Congresso Internacional da APRAPUI, 2009, São José do Rio Preto, SP. Anais (CD).

ANZALDÚA, G. (1999). Borderlands/ La Frontera. $2^{\mathrm{a}}$ ed. San Francisco: Aunt Lute Books.

ASSIS-PETERSON, A. A.; COX, M. I. P. (2007). Inglês em tempos de globalização: para além de bem e mal. Calidoscópio, v. 5, n. 1, p. 15-14, jan./abr.

BARCELOS, A. M. F. (1995). A cultura de aprender língua estrangeira (inglês) de alunos formandos de Letras. Dissertação (Mestrado em Linguística Aplicada) - Instituto de Estudos da Linguagem, Unicamp, Campinas.

BARCELOS, A. M. F.; BATISTA, F. S.; ANDRADE, J. C. (2004). Ser professor de inglês: crenças, expectativas e dificuldades dos alunos de Letras. In: Vieira Abrahão, M. H. (org.). Prática de ensino de lingua estrangeira: experiências e reflexões. Campinas: Pontes, p. 11-29.

BARCELOS, A. M. F. (1999). A cultura de aprender línguas [inglês] de alunos do curso de Letras. In: Almeida Filho, J. P. C. (org.). O professor de lingua estrangeira em formação. Campinas: Pontes, p. 157-177.

BASSO, E. A. (2006). Quando a crença faz a diferença. In: Barcelos, A. M. F.; Vieira Abrahão, M. H. (org.). Crenças e ensino de línguas: foco no professor, no aluno e na formação de professores. Campinas: Pontes, p. 65-85. 
BLOMMAERT, J. (2005) Discourse: a critical introduction. Cambridge: Cambridge University Press.

BORGES, T. D.; LAGO, N. A. do; FERNANDES, A. E. de P. (2009) Aprender inglês é "amar a nova língua": investigando as crenças de alunos formandos de letras (inglês). In: II Congresso Internacional da APRAPUI, 2009, São José do Rio Preto, SP. Anais (CD), São José do Rio Preto, SP.

BOURDIEU, P. (1973). Cultural reproduction and social reproduction. In: Brown, R. (ed.). Knowledge, education and cultural change. London: Tavistock, p. 71-112.

(1996). A economia das trocas linguísticas: o que falar quer dizer. Trad. Sérgio Miceli et al. São Paulo: USP. (Clássicos, 4).

CASTRO, S. T. R. de. (2001). Formação da competência do futuro professor de inglês. In: Leffa, V. J. (org.). O professor de línguas estrangeiras: construindo a profissão. Pelotas: Educat, p. 293-306.

CELANI, M. A. A. (2001). Ensino de línguas estrangeiras: ocupação ou profissão? In: Leffa, V. J. (org.). O professor de línguas estrangeiras: construindo a profissão. Pelotas: Educat, p. 21-40.

(2003). Um programa de formação contínua. In: CELANI, M. A. A. (org.). Professores formadores em mudança: relato de um processo de reflexão e transformação da prática docente. São Paulo: Mercado de Letras, p. 19-35.

CHARLOT, B. (2000). Da relação com o saber: elementos para uma teoria. Porto Alegre: Artmed.

COELHO, H. S. H. (2006). "É possível aprender inglês na escola?" Crenças de professores sobre o ensino de inglês em escolas públicas. In: Barcelos, A. M. F.; Vieira Abrahão, M. H. (org.). Crenças e ensino de línguas: foco no professor, no aluno e na formação de professores. Campinas: Pontes, p. 125-143.

COX, M. I. P.; ASSIS-PETERSON, A. A. (2008). O drama do ensino de inglês na escola pública brasileira. In: Assis-Peterson, A. A. (org.). Linguas estrangeiras: para além do método. Cuiabá: EdUFMT, p. 19-54.

GIMENEZ, T. (2004). Tornando-se professores de inglês: experiências de formação inicial em um curso de Letras. In: VIEIRA ABRAHÃO, M. H. (org.). Prática de ensino de língua estrangeira: experiências e reflexões. Campinas: Pontes, p. 171-187.

HOOKS, b. (1994). Teaching to transgress: education as the practice of freedom. New York: Routledge.

LACOSTE, Y. (2005). Por uma abordagem geopolítica da difusão do inglês. In: Lacoste, Y.; Rajagopalan, K. (org.). A geopolítica do inglês. Trad. Marcos Marciolino. São Paulo: Parábola Editorial, p. 7-11.

LEFFA, V. J. (2001). Aspectos políticos da formação do professor de língua estrangeira. In: LEFFA, V. J. (org.). O professor de linguas estrangeiras: construindo a profissão. Pelotas: Educat, p. 333-355.

LIN, A. M. Y. (1999). Doing English lessons in the reproduction or transformation of social worlds? TESOL Quarterly, v. 33, n. 3, p. 393-412.

MASTRELLA, M. R. (2007). Inglês como lingua estrangeira: entre o desejo do domínio e a luta contra a exclusão. Tese (Doutorado em Letras e Linguística) - Programa de Pós-graduação em Letras e Linguística, UFG, Goiânia. 
MELLO, H. A. B. de, REES, D. K.; TELES-BOTTER, G. A.; PESSOA, R. R. (1996). A opção por habilitação no curso de Letras. In: I Encontro de Política de Ensino de Línguas Estrangeiras, 1996, Florianópolis, SC. Anais, Florianópolis, SC.

MIGNOLO, W. D. (2003). Histórias locais / Projetos globais: colonialidade, saberes subalternos $e$ pensamento liminar. Trad. Solange Ribeiro de Oliveira. Belo Horizonte: Editora da UFMG.

MOITA LOPES, L. P. da. (2003). A nova ordem mundial, os parâmetros curriculares nacionais e o ensino de inglês no Brasil: a base intelectual para uma ação política. In: Barbara, L.; Ramos, R. de C. G. (org.). Reflexão e ações no ensino-aprendizagem de línguas. São Paulo: Mercado de Letras, p. 29-57.

OLIVEIRA, E.; MOTA, I. O. (2003). O ensino de língua inglesa na educação básica: entre a "qualidade" dos cursos de idioma de iniciativa privada e o silenciamento das escolas públicas estaduais paulistas. Trabalhos em Linguística Aplicada, v. 42, p. 125-134.

ORTIZ, R. (2004). As ciências sociais e o inglês. Revista Brasileira de Ciências Sociais, v. 19, n. 54, p. $5-23$. . (2006). Mundialização: saberes e crenças. São Paulo: Brasiliense.

PENNYCOOK, A. (2007). The myth of English as an international language. In: Makoni, Sinfree; Pennycook, A. (ed.). Disinventing and reconstituting languages. Clevedon: Multilingual Matters, p. 90-115.

PESSOA, R. R.; SEBBA, M. A. Y.; GOMES, V. M. de A. (2009) A formação do professor de inglês nas grades curriculares anual e semestral do curso de Letras da UFG. Signótica, v. 21, n. 2, p. 417-447, jul./dez.

RAJAGOPALAN, K. (2001). The politics of language and the concept of linguistic identity. CAUCE, Revista de Filología y su Didáctica, n. 24, p. 17-28.

VIEIRA ABRAHÃO, M. H.; PAIVA, V. L. M. O. (2000) Repensando o curso de Letras: habilitação em língua estrangeira. In: Leffa, V. J. [Compilador]. TELA [Textos em Linguística Aplicada] [CD-ROM]. Pelotas: Educat.

Recebido: 15/12/2011

Aceito: 18/02/2013 
